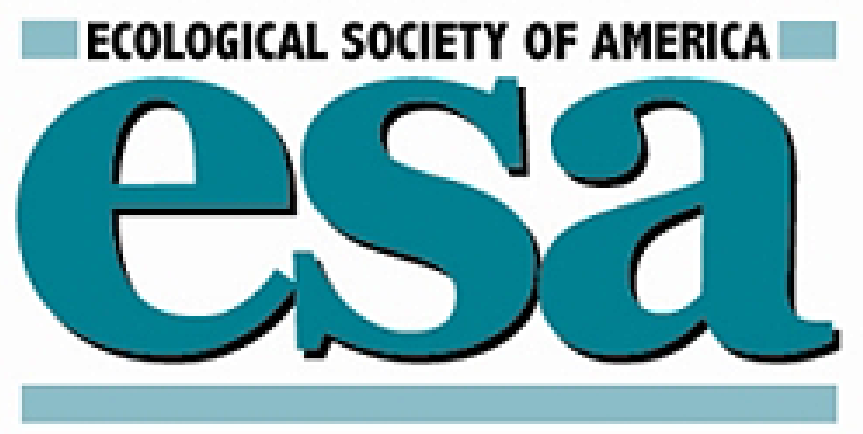

Future declines of the binational Laurentian Great Lakes fisheries: the importance of environmental and cultural change

Author(s): John D Rothlisberger, David M Lodge, Roger M Cooke and David C Finnoff

Source: Frontiers in Ecology and the Environment, Vol. 8, No. 5 (June 2010), pp. 239-244

Published by: Ecological Society of America

Stable URL: http://www.jstor.org/stable/27809110

Accessed: 08/07/2014 11:40

Your use of the JSTOR archive indicates your acceptance of the Terms \& Conditions of Use, available at http://www.jstor.org/page/info/about/policies/terms.jsp

JSTOR is a not-for-profit service that helps scholars, researchers, and students discover, use, and build upon a wide range of content in a trusted digital archive. We use information technology and tools to increase productivity and facilitate new forms of scholarship. For more information about JSTOR, please contact support@jstor.org. 


\title{
Future declines of the binational Laurentian Great Lakes fisheries: the importance of environmental and cultural change
}

\author{
John D Rothlisberger ${ }^{1 *}$, David M Lodge ${ }^{1}$, Roger M Cooke ${ }^{2}$, and David C Finnoff ${ }^{3}$
}

It is increasingly clear that future long-term environmental challenges (eg climate change) are being driven by economic and cultural choices, as well as by physical and biological mechanisms. We looked at the extent to which these apply to potential future changes in fisheries in the Laurentian Great Lakes. These fisheries rank among the most valuable freshwater fisheries in the world, but have declined markedly in recent decades. To investigate how these fisheries might develop in the future, we elicited projections from experts in fisheries and related fields. Experts provided assessments on variables relating to US and Canadian commercial (pounds landed) and sport (participation and expenditures) fisheries for the years 2006 and 2025. We measured each expert's ability to quantify their uncertainty, producing performance-weighted combinations of expert estimates. All experts expected commercial fisheries to decline from 2006 to 2025, with greater declines in the US (25\%) than in Canada (9\%). Expectations for sport fishing differed more between lakes and less between countries, with median expected declines ranging from $1 \%$ to $13 \%$. Experts attributed expected declines primarily to changes in economic market demands and shifts in societal interests. Increased attention to social and economic trends could aid Laurentian Great Lakes fishery policy and management.

Front Ecol Environ 2010; 8(5): 239-244, doi:10.1890/090002（published online 2 Dec 2009)

$\mathbf{R}^{\mathrm{e}}$ ecent Intergovernmental Panel on Climate Change reports indicate that future climate will, in part, be a function of human choices regarding cultural and economic priorities (Parry et al. 2007). Recent experience with marine and freshwater fisheries in many countries also demonstrates the importance of the interaction of cultural practices and economic policies with fish population dynamics in determining the current status of fish stocks (Hilborn et al. 2003). Here, we apply this perspective of co-determination - the two-way interactions between human and natural systems (Crocker and Tschirhart 1992; Knowler and Barbier 2001) - by using structured expert judgment (SEJ) to estimate the future magnitude of fisheries-derived ecosystem services in the Laurentian Great Lakes (GL).

The commercial and sport fisheries of the GL are valuable natural resources that have been exploited extensively since European colonization, but have changed substantially in recent decades as a result of various factors, including water-quality regulation, increased societal interest in recreational as opposed to commercial fishing, and invasions by non-indigenous species (Figure 1 ). Beginning in the early $1800 \mathrm{~s}$, humans have extracted fishery resources from the GL at a rapid and sometimes

${ }^{1}$ Center for Aquatic Conservation and Department of Biological Sciences, University of Notre Dame, Notre Dame, IN *(jrothlis@ gmail.com); ${ }^{2}$ Resources for the Future, Washington, DC, and Technical University of Delft, Delft, Netherlands; ${ }^{3}$ Department of Economics and Finance, University of Wyoming, Laramie, WY unsustainable pace (Bogue 2000). Growing human populations and increasing prosperity brought more resource extraction, more intensive agriculture, and the development of various industries, including a wide variety of GL-based recreational activities. However, erosion and water pollution - byproducts of agriculture and industry modified the GL environment, often to the detriment of fish populations that had been instrumental in promoting economic growth (Beeton 1969).

Other environmental changes that accompanied human population growth and economic activity have also affected GL fish; these include the construction of dams on GL tributaries, the opening of shipping canals, the intentional stocking of non-native fish species, and the inadvertent introduction of numerous other nonnative taxa via multiple vectors (Mills et al. 1993; Coon 1999; Ricciardi 2006).

We used SEJ (Cooke 1991) to incorporate multiple interacting social, economic, political, and environmental factors in ecosystem-scale assessments of the potential future condition of GL fisheries. For decades, fisheries management councils have used approaches based on informal expert opinion to set allowable catch quotas (eg Sazonova et al. 1999; Boydstun 2001), but our study is the first to use expert opinion to forecast the commercial or recreational harvest of fish stocks.

Specifically, we used SEJ to estimate the magnitude of changes in GL fisheries between 2006 and 2025, and to quantify the uncertainty surrounding each prediction. To identify likely drivers of change - including continuing 


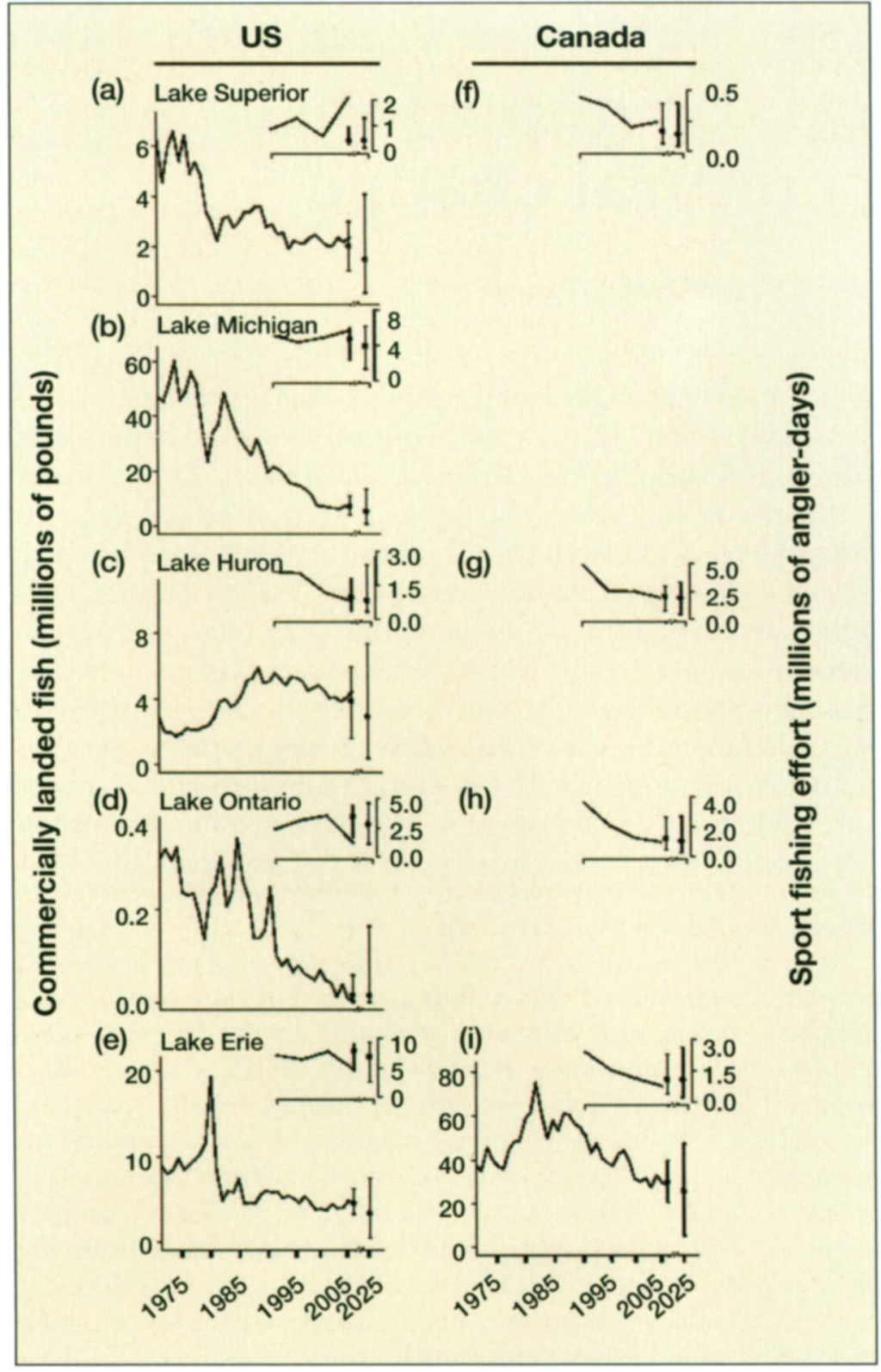

Figure 1. Historical and projected commercial and recreational fisheries in the US and Canadian waters of the Great Lakes (GL). Angler effort in recreational fisheries is shown as insets in the upper right of each panel. Vertical range bars are performance-based combinations of expert assessments (WebTable 1) where lower and upper limits show, respectively, 5th and 95th percentiles of the combined expert subjective probability distributions. Filled circles depict the 50th percentile of each distribution. Note different vertical scales across countries, lakes, and fishery types. Canadian commercial catch (panel $i$ ) is for all Canadian waters of the GL. In the past decade, $75 \%$ of Canadian commercial catch has come from Lake Erie. Historical recreational fisheries data are from USFWS (2007). Commercial catch data dating back to 1971 were obtained for the US from the US Geological Survey (USGS) Great Lakes Science Center and for Canada from Fisheries and Oceans Canada.

natural and anthropogenic stresses such as future biological invasions, regional climate change, economic market changes, and developing trends in pastime activities experts provided rationales, explaining the reasoning behind their predictions. Understanding these drivers could guide research priorities and assess the potential efficacy of natural resource policy and management.

\section{Methods}

In SEJ, experts are seen as independent scientific instruments that provide assessments of future conditions, based on current trends and on past and possible future drivers of variability. Expert estimates are obtained via an individual interview with each expert. In their interview, each expert responds to the same series of questions, with no knowledge of the other experts' responses. The actual values for all of the variables that experts estimate are unknown at the time of questioning, but when the actual values of some of these variables become known - experts can be assessed relative to the precision and accuracy of their estimates. More specifically, the questions with known answers (12 of 31 questions in this study) allow investigators to treat expert median estimates and uncertainties as hypotheses that are then compared against new data (ie the answers to these questions) to assess the statistical accuracy and precision of each expert's estimates, thereby determining how well calibrated each expert is. The judgments of multiple experts are then combined into a single estimate that accounts for the calibration of each expert and is bounded by an uncertainty range (Cooke 1991).

\section{Expert selection and interviews}

Based on publication record, individual area of expertise (eg food-web ecology, environmental economics, fishery management), and recommendations from senior GL researchers, we invited nine individuals with excellent general knowledge and wide credibility on the social and biological dynamics of the GL region to participate (WebTable 2). We randomly assigned each expert a unique number, making it impossible to link specific assessments to individual participants.

Before the interview, each expert received the elicitation survey, which contained all the questions they would be asked, and a briefing book with historical data on GL fisheries and training materials on uncertainty and probabilistic assessment. Both the briefing book and the survey are available at http://aquacon.nd.edu/ research/. We encouraged the nine experts to use the book and any other materials of their choosing as much as they wished before and during their interviews. 
We interviewed each expert individually during October 2007. Each expert provided the 5th, 50th, and 95th percentiles of their subjective cumulative probability density function for 31 variables relevant to GL fisheries.

A typical pair of questions took the following form:

How many total pounds of commercial fish were landed from the US waters of Lake Erie in 2006?

$$
5 \%
$$$$
50 \%
$$

$95 \%$

How many total pounds of commercial fish WILL BE landed from the US waters of Lake Erie in 2025?

$$
5 \%
$$$$
50 \%
$$$$
95 \%
$$

Following each such pair of questions, we asked the experts to provide their rationale for the predicted changes in the variable between 2006 and 2025, identifying - if possible - the most important expected driver of change. We made notes and audio recordings of these responses.

\section{Analysis, combination, and reporting of results}

We report the experts' answers as individual assessments (WebFigures 1, 2, and 3) and as combined assessments for each variable (Figures 1 and 2). We combined expert assessments in two ways: (1) equal weight given to each expert and (2) expert weight based on calibration variable performance (Cooke 1991).

For each variable, we calculated the expected percent change between 2006 and 2025, and the associated uncertainty range. To make this calculation, we assumed independence of all variables and used a convolution algorithm to obtain the distribution of the differences between the 2006 and 2025 performance-based combination (PBC) distributions. We then divided the 5th, 50th, and 95 th percentiles of this distribution of differences by the appropriate 2006 median assessment and multiplied by $\left.100\left(\left[(2025-2006)_{5 \text { th, } 50 \text { th, or } 95 \text { th percentile }}\right) / 2006_{50 \text { th }}\right] * 100\right)$ to find expert-expected percent change. We extracted from the experts' rationales the driver of change each one identified as being most important to the future condition of GL fisheries. We also tabulated how many experts mentioned each driver of change (Figure 3 ).

\section{Results}

Equal weighting and $\mathrm{PBC}$ of expert assessments produced roughly similar median results. However, the equal weight combination was statistically inaccurate, whereas the PBC variables were statistically accurate (WebTable 1). Furthermore, the PBC allowed us to weight experts according to the precision and accuracy of their assessments (WebTable 1; WebFigures 1 and 2). We therefore report here only the results of the PBC. In our figures, we provide $\mathrm{PBC}$ uncertainty ranges (Figure 1 ) and probability distributions (Figure 2). In the text, we focus on median values, because these reflect the outcomes experts saw as most likely, and experts' rationales for their predictions correspond to these medians. Moreover, because we assumed independence between 2006 and 2025 when calculating projected percent changes, the ranges of these projections (Figures 1 and 2) are overly broad relative to the experts' narrative descriptions of how GL fisheries might change between 2006 and 2025.

\section{US commercial fishery}

The actual 2006 commercial catch data are enclosed in the PBC 90\% uncertainty estimates in all cases (Figure 1; WebTable 1). The PBC projected $19-31 \%$ decreases in commercial catches in 2025 for Lakes Superior, Michigan, Huron, and Erie (Figure 2). Six of the nine experts (67\%) indicated that the most important reason for predicted declines in commercial fishing was the decreasing economic viability of the fishery, resulting from a combination of cheaper supplies of fish entering the marketplace (eg aquaculture) and sport fishing continuing to receive political preference (eg higher allocation of total allowable catch quotas). The other experts gave invasive species impacts (one expert), climate change (one expert), and limitations on ecosystem productivity (one expert) as the primary causes of declines. The most commonly mentioned reasons for decline were invasive species, economic markets, and fishery policy (Figure 3 ).

\section{Canadian commercial fishery}

Historical data on individual lakes were not available for the Canadian commercial fishery; experts were therefore asked for estimates on landings aggregated from all Canadian waters of the GL. The PBC assessments accurately predicted the 2006 Canadian commercial catch (Figure 1) and forecast that Canadian commercial landings will decline $9 \%$ by 2025 (Figure 2). Five of the nine experts $(56 \%)$ cited failing economic viability of the fishery as the main reason for the predicted declines. Of the remaining experts, one attributed expected declines primarily to food-web disruptions by invasive species. Three others predicted stability or even a slight increase in the Canadian commercial catch by 2025 , owing largely to strong political support for commercial fishing in Canada. Invasive species and changing economic markets were the most commonly mentioned factors driving declines or limiting growth (Figure 3).

\section{US sport fishery}

The PBC estimates were not as accurate for 2006 sport effort as for commercial landings, but the actual data for 2006 fell within the $90 \%$ uncertainty range for four of 


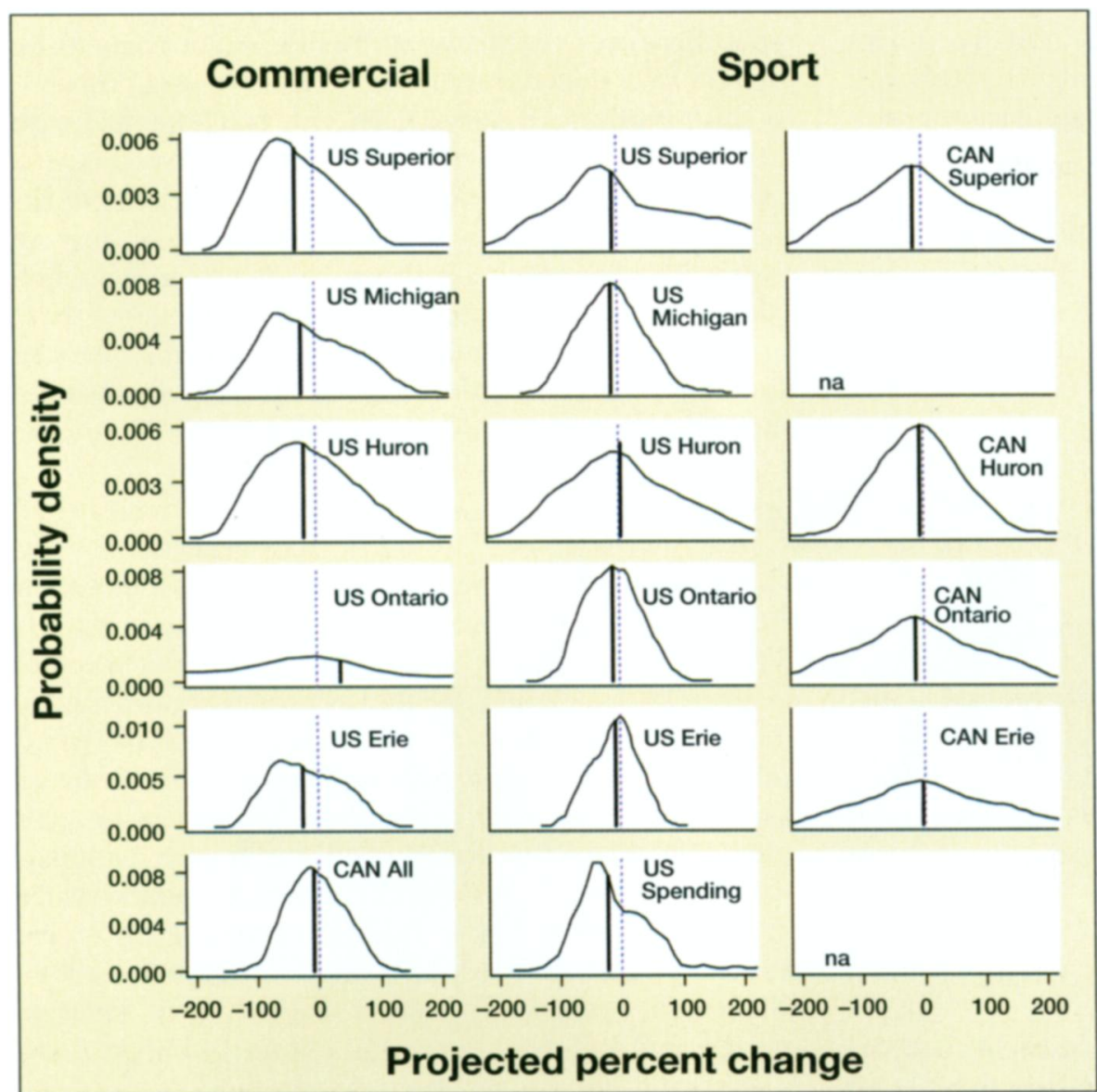

Figure 2. Probability density functions of PBC-projected percent change between 2006 and 2025 in US and Canadian commercial fish landings (pounds landed), and sport fishing effort (angler-days) and expenditures (2007 US\$). Vertical black lines show median of each distribution. Vertical dotted lines provide a reference to zero percent change. Note that, even though most distributions extend to the left of $-100 \%$, the value of these variables in 2025 cannot be less than zero. na = not applicable.

The PBC performed well in predicting 2006 angler expenditures aggregated over all lakes (WebFigure 3 ), which are expected to fall by $24 \%$ (or about US $\$ 330$ million, expressed in 2007 US\$) by 2025 (USFWS 2007; Figure 2).

\section{Canadian sport fishery}

The PBC forecast that effort in Canadian sport fisheries will decline $1-12 \%$ by 2025 (Figures 1 and 2). Most experts (six out of the nine) expressed greater uncertainty in their predictions for Canadian sport fisheries than for their US counterparts, partially because of their current small size, possibly causing volatility. Five experts indicated changing trends in pastimes would be the primary driver of declines, but two said invasive species impacts would be the main driver of declines. On the other hand, one expert expected stability in the fishery and one expected a slight increase in angler effort. Shifts away from fishing as a pastime and harm caused by invasive species were mentioned most often as drivers of declines for the Canadian sport fishery (Figure 3).

\section{Discussion}

the five lakes (Figure 1). For four lakes, the PBC projected $9-13 \%$ declines in fishing effort in 2025 relative to that in 2006. In contrast, the PBC predicted that effort will increase $1 \%$ in Lake Huron (Figure 2); several experts attributed this projected increase to 2006 being a particularly bad year for Lake Huron because of food-web disruptions involving alewife (Alosa pseudoharengus) population declines. Six out of the nine experts $(67 \%)$ gave as their primary reason for expected declines in angling effort - reduced cultural interest in consumptive outdoor recreation (eg fishing) and, for the population segment still interested in angling, a preference for inland waterways over the GL. These experts attributed the shifting preference away from the GL to the rising costs of participation in GL fishing, as nearshore fisheries decline and as costs climb for equipment and fuel to participate in offshore fishing. Of the remaining experts, one believed that invasive species will be the primary reason for declines by 2025 , one expected stability in angler participation, and one did not identify a primary cause for declines. Invasive species were the most commonly mentioned secondary driver of declines (Figure 3 ).

\section{Drivers of change in GL fisheries}

According to experts, the projected declines in fisheries in the US and Canadian waters of the GL (Figure 2) will largely be a function of social trends, economic conditions, and political decisions (Figure 3). Thus, when considering the future of fisheries in the GL, a comprehensive view of societal dynamics and interactions between biological and economic systems must be taken into account. This is especially the case for the economically valuable sport fisheries (GLFC 1988), on which we focus our discussion here.

The importance of biological and cultural factors on GL fisheries is clear when considering the rehabilitation of self-sustaining populations of native species in the GL. Lake trout (Salvelinus namaycush) rehabilitation is a major emphasis in GL fishery management, particularly for US federal agencies (Holey et al. 1995; Knuth et al. 1995). Using Lake Superior as a case study, Kitchell et al. (2000) point out that the ecological turnover rate of the historical fish community in the upper GL - consisting of lake trout and lake herring (Coregonus artedii) as primary predator and prey - was much slower than the turnover 


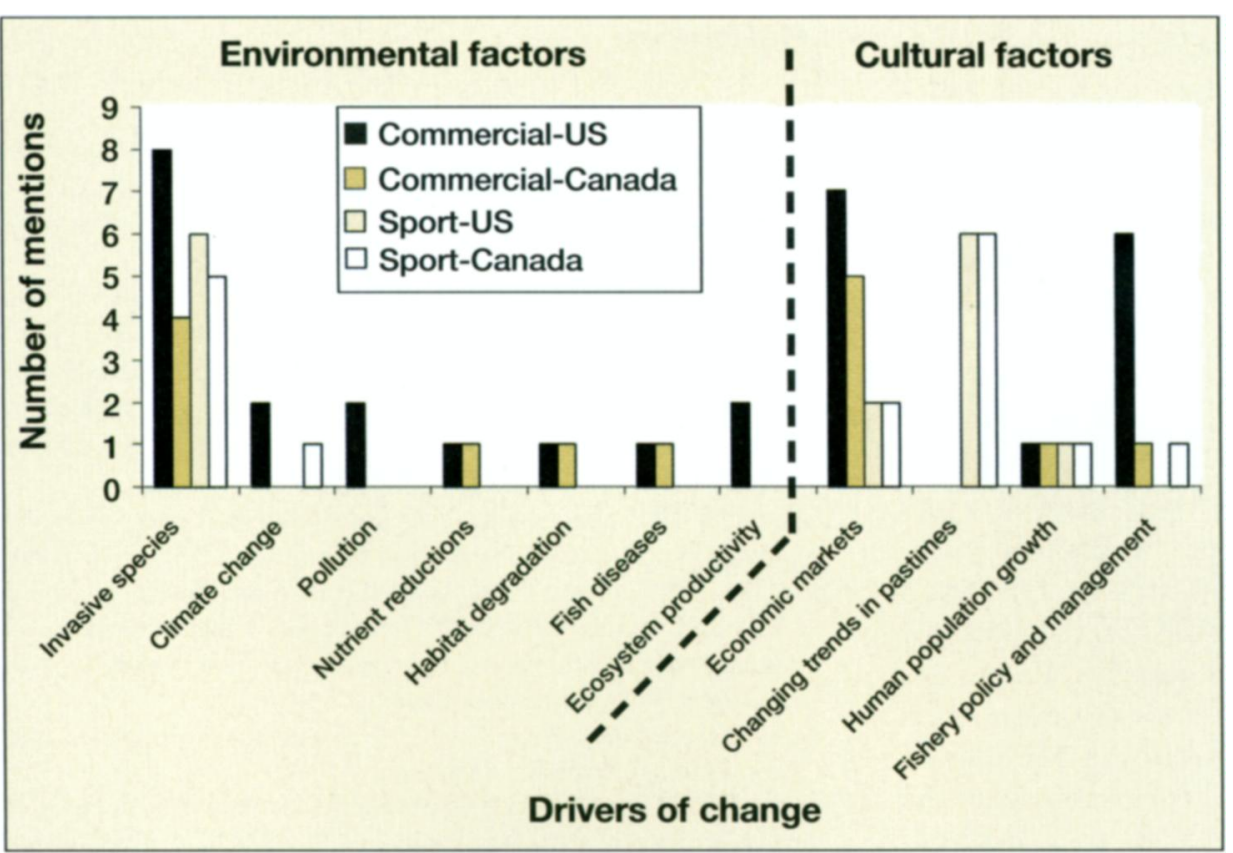

Figure 3. Number of experts that mentioned various potential drivers of change in explaining their expectations for declines in US and Canadian commercial and sport fisheries between 2006 and 2025.

rate of the currently predominant Pacific salmon (Oncorhynchus spp)-alewife and rainbow smelt (Osmerus mordax) predator-prey system. They conclude that further restoration (ie augmentation) of lean lake trout stocks, which is currently specified as one of the major management goals in Lake Superior (GLFC 2003), will be extremely challenging. In fact, Lake Superior may be as close to a restored state in this regard as possible; hence, any continued efforts to enhance lean lake trout populations in Lake Superior may unintentionally force declines in Pacific salmon, a valuable component of the sport fishery, possibly reducing angler participation and, consequently, economic benefits (Kitchell et al. 2000).

This apparent conflict in objectives in Lake Superior, however, may be a false dilemma, as may be the case with other similar situations across the GL, because cultural trends may now be more important drivers of fishery participation levels than are stock sizes. Even as managers actively try to balance recreational fishery (Pacific salmon) enhancement with native fish community (lake trout) restoration, experts expressed considerable uncertainty regarding the value of these efforts for improving fisheries, mainly because of doubts as to whether angler effort will increase in response to these management efforts. Of course, management decisions regarding the restoration of native communities and the enhancement of particular fish stocks are complex issues, the goals of which certainly extend beyond creating successful fisheries (eg intrinsic value of native species). Our focus here, however, is on expectations for GL fisheries and their expected drivers of change.

Therefore, increased consideration of the response of anglers to changes in fish stocks relative to cultural change could help to inform fishery policy and manage- ment. For example, if the decision were made to try to increase participation levels in GL sport fisheries in the coming years, it would be valuable to know the tradeoffs between investing in programs to improve sport fish stocks versus efforts to recruit more anglers to the fishery through advertising and educational programs. According to our experts, the latter would probably be a more effective tool in growing or maintaining the fishery. This is because, as long as the target species are not extremely scarce, most of the projected declines in sport fishing on the GL will occur as a result of dwindling societal interest in the pastime, driven by less discretionary free time and the pursuit of other pastimes, not by declining abundance of target species. This is counter to some reports that fishing pressure has previously responded to shifts in abundance of popular species in the GL (eg the spike in Ohio fishing license sales in the 1980s in response to walleye recovery in Lake Erie [Hatch et al. 1987], the drop in Lake Huron angling in the 2000s when the Chinook salmon (Oncorhynchus tshawytscha) fishery collapsed [Dobiesz et al. 2005]) and bears further investigation.

\section{Conclusions}

Hypotheses about the highly complex interactions between ecological systems and human society in the GL region could never be tested directly with standard research methods, even if an enormous budget were available to support such research. SEJ provides a tool to overcome this obstacle and to predict future states of the GL fisheries, with explicit attention given to the substantial uncertainties involved. Results that suggest the importance of social and cultural factors in the future of GL ecosystem services do not in any way diminish the wellknown importance of environmental degradation and unsustainable harvest practices that have led to past stock collapses and production declines in many of the world's most important marine (Pauly et al. 2002; Hilborn et al. 2003) and freshwater (Allan et al. 2005) fisheries. Indeed, the importance of cultural factors relative to environmental ones (Figure 3) may be of greater magnitude for the GL than for other major fisheries because of the growing primacy of sport fishing in the lakes. Our study underscores the continued and increasing relevance of cultural factors, including economic considerations, when designing plans and setting objectives for fishery management, 
particularly in the North American GL. Specifically, further research on the drivers of change in GL fisheries especially sport fisheries - is needed to support scientifically sound and socially beneficial fishery policy and management. The primary drivers of change that experts identified point the way for future inquiries, particularly into the causes and consequences of people spending less time fishing recreationally on the GL.

\section{Acknowledgements}

We thank the nine experts for their participation. The NOAA National Sea Grant Program (Award \#NA16RG2283) through the Illinois-Indiana Sea Grant College Program (subaward \#2003-06727-10) partially funded this research. The US Environmental Protection Agency's (US EPA's) National Center for Environmental Economics also provided support (Contract \#EP-W-05022). A Schmitt Graduate Research Fellowship from the University of Notre Dame supported JDR. Special thanks to S Nelson of the USGS Great Lakes Science Center for help in obtaining the 2006 US commercial fish landing data. Feedback from R Keller and D Yeo improved the manuscript. Although the research described in this article has been funded in part by the US EPA, the opinions expressed here are those of the authors, and do not necessarily express the views of the US EPA.

\section{Saudi Aramco seeks a full-time, experienced Terrestrial Ecologist}

to provide technical support and expertise in desert ecology, protection of terrestrial ecosystems, and protection of threatened or endangered species affected by company projects and operations.

The terrestrial ecologist will assist in scoping and reviewing Environmental Impact Assessments prepared for major capital projects and will provide expert advice and technical assistance. The location is Dhahran, Saudi Arabia.

The position is open until filled.

Bachelor's degree in relevant discipline required; master's degree preferred. Must have verifiable relevant experience, including field work in desert environments, preferably in the Middle East. References required.

See www.jobsataramco.com for details or contact james.findley@aramco.com

\section{ارامكو السمودية Saudi Aramco}

\section{References}

Allan JD, Abell R, Hogan Z, et al. 2005. Overfishing of inland waters. BioScience 55: 1041-51.

Beeton AM. 1969. Changes in the environment and biota of the Great Lakes. In: Rohlich GA (Ed). Eutrophication: causes, consequences, correctives. Washington, DC: National Academy of Sciences.

Bogue MB. 2000. Fishing the Great Lakes: an environmental history, 1783-1933. Madison, WI: University of Wisconsin Press.

Boydstun LB. 2001. Ocean salmon fishery management. In: Brown RL (Ed). Fish bulletin 179: contributions to the biology of Central Valley salmonids, vol 2. San Diego, CA: Scripps Institution of Oceanography Library.

Cooke RM. 1991. Experts in uncertainty: opinion and subjective probability in science. New York, NY: Oxford University Press.

Coon TG. 1999. Ichthyofauna of the Great Lakes basin. In: Taylor WW and Ferreri CP (Eds). Great Lakes fisheries policy and management: a binational perspective. East Lansing, MI: Michigan State University Press.

Crocker TD and Tschirhart J. 1992. Ecosystems, externalities, and economies. Environ Resour Econ 2: 551-67.

Dobiesz NE, McLeish DA, Eshenroder RL, et al. 2005. Ecology of the Lake Huron fish community, 1970-1999. Can J Fish Aquat Sci 62: 1432-51.

GLFC (Great Lakes Fishery Commission). 1988. Economics of Great Lakes fisheries: a 1985 assessment. Ann Arbor, MI: Great Lakes Fishery Commission. Technical report 54.

GLFC (Great Lakes Fishery Commission). 2003. Fish community objectives for Lake Superior. Ann Arbor, MI: Great Lakes Fishery Commission. Special publication 03-01.

Hatch RW, Nepszy SJ, Muth KM, and Baker CT. 1987. Dynamics of the recovery of the western Lake Erie walleye (Stizostedion vitreum vitreum) stock. Can J Fish Aquat Sci 44: 15-22.

Hilborn R, Branch TA, Ernst B, et al. 2003. State of the world's fisheries. Annu Rev Env Resour 28: 359-99.

Holey ME, Rybicki RW, Eck GW, et al. 1995. Progress toward lake trout restoration in Lake Michigan. J Great Lakes Res 21: 128-51.

Kitchell JF, Cox SP, Harvey CJ, et al. 2000. Sustainability of the Lake Superior fish community: interactions in a food web context. Ecosystems 3: 545-60.

Knowler D and Barbier E. 2001. Importing exotic plants and the risk of invasion: are market-based instruments adequate? Ecol Econ 52: 341-54.

Knuth BA, Lerner S, Connelly NA, and Gigliotti L. 1995. Fishery and environmental managers' attitudes about and support for lake trout rehabilitation in the Great Lakes. J Great Lakes Res 21: 185-97.

Mills EL, Leach JH, Carlton JT, and Secor CL. 1993. Exotic species in the Great Lakes: a history of biotic crises and anthropogenic introductions. J Great Lakes Res 19: 1-54.

Parry ML, Canziani OF, Palutikof JP, et al. (Eds). 2007. Climate change 2007: impacts, adaptation and vulnerability. Contribution of Working Group II to the Fourth Assessment Report of the Intergovernmental Panel on Climate Change. Cambridge, UK: Cambridge University Press.

Pauly D, Christensen V, Guenette S, et al. 2002. Towards sustainability in world fisheries. Nature 418: 689-95.

Ricciardi A. 2006. Patterns of invasion in the Laurentian Great Lakes in relation to changes in vector activity. Divers Distrib 12: 425-33.

Sazonova L, Osipov G, and Godovnikov M. 1999. Intelligent system for fish stock prediction and allowable catch evaluation. Environ Modell Softw 14: 391-99.

USFWS (US Fish and Wildlife Service). 2007. 2006 National survey of fishing, hunting, and wildlife-associated recreation. Washington, DC: US Fish and Wildlife Service. 